\title{
Fetus in Fetu...A Rare Case Report!!!
}

\author{
Dr. G.S.S. Mohapatra ${ }^{1}$,Dr. Amit Agrawal ${ }^{2}$ \\ ${ }^{1}$ Dr. G.S.S. Mohapatra, Sr. Consultant Amri Hospital, Bhubaneswar \\ ${ }^{2}$ Dr.Amitagrawal Sr. Resident Amri Hospital Bhubaneswa
}

\begin{abstract}
Fetus in fetu is a rare congenital anomaly, commonly of monozygotic twin, in which one fetus grows inside another fetus. It is a parasitic twin, usually presents as an abdominal mass. Most common site is retro peritoneum but it can present anywhere. It should be differentiated from teratoma which has no axial arrangement and has got definite malignant potential. Different imaging modalities can help in diagnosis. Complete excision is curative. Here we present a case of fetus in fetu which was diagnosed in antenatal period. After delivery diagnosis confirmed and complete surgical excision done.

Case Report: A 30-year-old primigravida, presented to the O\&G OPD at 36 weeks gestation for routine antenatal check up. Her USG showed a fetus of 36weeks gestation with cephalic presentation, AFI 10,placenta fundal with a well defined solid cystic lesion of $6.8 \times 5.3 \mathrm{~cm}$ seen in left suprarenal area of fetus along with multiple well formed bony structures like femur and pelvic bone within the solid component. No significant vascularity was seen. Provisional diagnosis of fetus in fetu was made. On routine blood investigation she was found to be anaemic with peripheral smear showing microcytic hypochromic anaemia. She was sickling $+v e$. There was no history of any maternal illness during pregnancy, no history of any radiation or drug intake during pregnancy. She was planned for elective caesarean section keeping blood ready. Intraoperative period was uneventful.She delivered a male baby which was immediately handed over to paediatrician. Baby was kept under observation. X ray abdomen showed a soft tissue mass in left renal area with areas of irregular calcification, displacing bowel loops to right.USG abdomen showed a left suprarenal mass with a provisional diagnosis of fetus in fetu. CT scan showed a suprarenal mass of $7 \times 6.7 \times 6.8 \mathrm{~cm}$ with irregular calcification displacing spleen anteriorly and left kidney inferiorly with no lymphadenopathy. Laparotomy was done by left upper transverse incision .A cystic lesion was noted in the left retroperitoneum with structures resembling thigh, leg and bones of lower limb. Mass was displacing the left kidney downwards. Mass was excised, and sent for HP study. Biopsy revealed brain like tissues, limbs and gut like structures. Diagnosis of fetus in fetu was confirmed.
\end{abstract}

\section{Discussion}

The term Fetus in fetu was coined by Meckel. Fetus-in-fetu is usually single, however possibly multiple, aberration of monozygotic diamniotic twinning in which unequal division of the totipotent inner cell mass of the developing blastocyst leads to the inclusion of a smaller cell mass within a maturing sister embryo.[1] Thakral et al.[2] reported equal male and female prevalence but Patankar et al.[3] and Federici et al.[4] noted a 2:1 male predominance. The common presentation of fetus in fetu is most commonly in the abdomen, almost $80 \%$ in the retroperitoneum followed by abdomen, scrotum, cranium, kidneys, adrenals, mediastinum, and lymph nodes etc.

Fetus in fetu produces symptoms due to mass effect leading to distension, difficulty in feeding, vomiting, jaundice, urinary retention. Preoperative diagnosis can be made on plain radiographs and CT scan/MRI [5]. The presence of vertebrae, long bones, bones of hands and feet etc are the common radiological findings. Visualization of a non-homogenous mass with bones especially vertebrae is considered pathognomonic of Fetus in fetu. Failure to visualize vertebrae however does not rule out possibility of Fetus in fetu [6]. The other frequent differential diagnosis is teratoma [7].

Pathological controversy arises during differentiation of fetus in fetu from a mature or well organized teratoma. According to Willis,[8] the presence of axial skeleton with vertebral axis and an appropriate arrangement of other limbs and organs goes more in favor of fetus in fetu. No vertebral column was found even on pathological examination[9] Therefore, Gonzalez-Crussi suggested fetus in fetu to be applied to any structure in which the fetal form has a highly developed organogenesis or to the presence of vertebral axis. On the other hand, teratoma is an accumulation of pluripotent cells in which there is neither organogenesis nor vertebral segmentation.[10]

Complete excision of Fetus in fetu along with covering membrane is necessary, as a case of malignant transformation of left over membrane is reported in literature. These cases are monitored with alpha-fetoprotein or beta-HCG, along with ultrasound and other radiological investigations [11,12]. 


\section{Conclusion}

Fetus in fetu is a rare entity but can be diagnosed if it was kept in differential diagnosis of any abdominal mass in infancy or childhood, sometimes can be suspected from antenatal ultrasound.

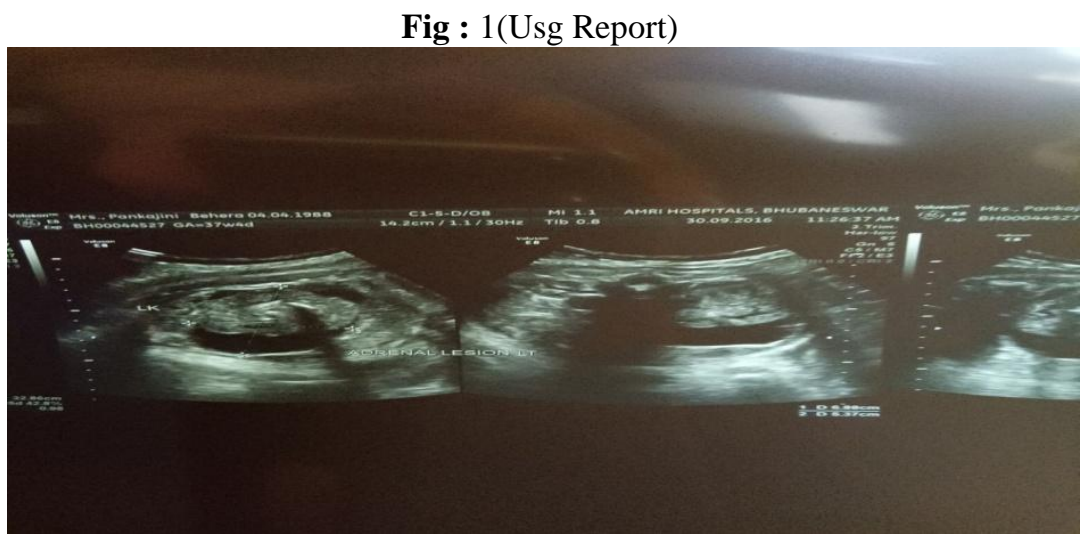

Fig -2 (Ct Scan Abdoemn) suprarenal mass of $7 \times 6.7$ x $6.8 \mathrm{~cm}$ with irregular calcification displacing spleen anteriorly and lt kidney inferiorly

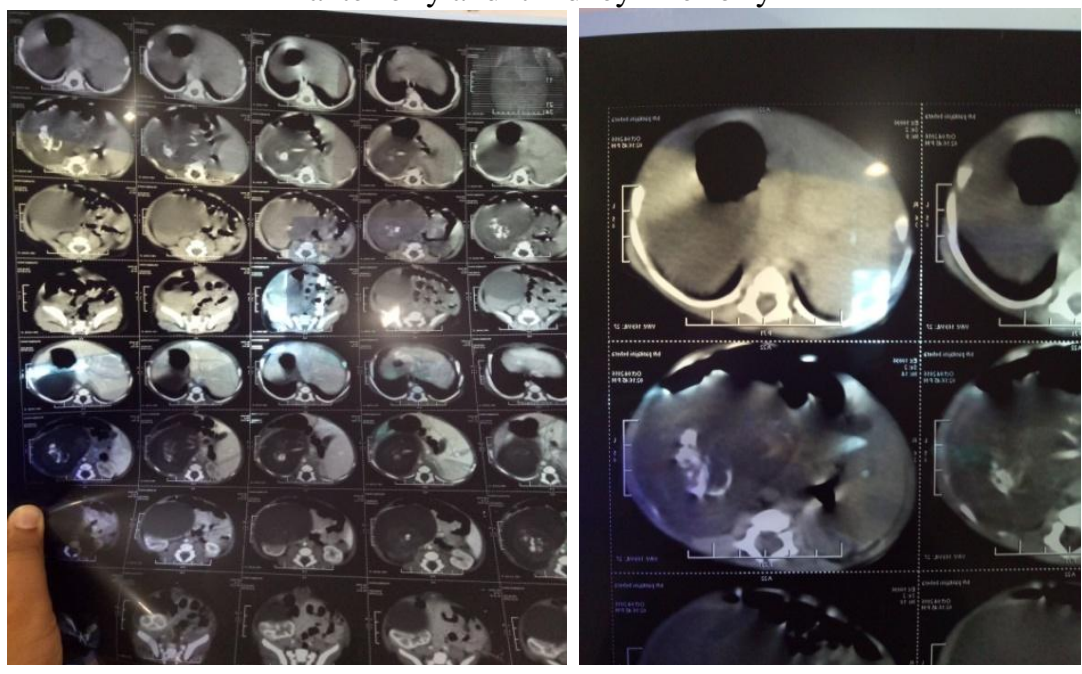

\section{References}

[1]. Lewis RH. Fetus in fetu and retroperitoneal teratoma. Arch Dis Child. 1960;36:220-6.

[2]. Thakral CL, Maji DC, Sajwani MJ. Fetus-in-fetu: a case report and review of the literature. J Pediatr Surg.1998;33(9):1432Patankar T, Fatterpekar GM, Prasad S, Maniyar A, Mukherji SK. Fetus in fetu: CT appearance-report of two cases. Radiology. 2000;214(3):735-7.

[3]. Federici S, Ceccarelli PL, Ferrari M, Galli G, Zanetti G, Domini R. Fetus in fetu: report of three cases and review of the literature. Pediatr Surg Int. 1991;6(1):60-5.

[4]. Eng HL, Chuang JH, Lee TY, Chen WJ. Fetus in fetu: a case report and review of the literature. J Pediatr Surg. 1989; $24: 296-9$.

[5]. Federici S, Ceccarelli PL, Ferrari M, Galli G, Zanetti G, Domini R. Fetus in fetu. Report of three cases and review of the literature. Pediatr Surg Int. 1991; 6: 60-5.

[6]. Kurdi AM, Al-Sasi OM, Asiri SM, Al-Hudhaif JM. Fetus-in-fetu. Imaging and pathology. Saudi Med J.2012; 33: 444- 8.

[7]. Willis RA. The borderland of embryology and pathology. 2nd ed. London: Butterworths Washington DC; 1962. pp. $442-46$.

[8]. Gonzalez-Crussi F. Extragonadal teratomas (Atlas of tumor pathology) Washington, DC: Armed Forces Institute of Pathology; 1982.

[9]. Kim OH, Shinn KS. Postnatal growth of fetus-in-fetu. Pediatr Radiol. 1993;23(5):411-2.

[10]. Joshi M, Parelkar S, Shah H, Agrawal A, Mishra P. Foetus in fetu with common bile duct injury: a case report and review of literature. ANZ J Surg. 2009; 79: 651-2.

[11]. Hopkins KL, Dickson PK, Ball TI, Ricketts RR, O'Shea PA, Abramowsky CR. Fetus-in-fetu with malignant recurrence. J Pediatr Surg. 1997; 32: 1476-9. 